unquestionably, very far-fetched. Patrick will find it hard to convince me or the average man in the street that his phylogenetic viewpoint, with the recapitulation theory overworked, is responsible for the present war in Europe.

All in all, allowing for the fundamental error mentioned above, the volume presented to us is well worth owning and the reader of these pages is urged to read it.

The plea for more rest and relaxation is one in which we must all join. Most of us are being overworked; hence the inter-relationship of this question with problems of economics, politics and the like.

\title{
Meyer Solomon.
}

Being well-born, Michael $F$. Guyer, $P h$. $D$, the BobbsMerrill Company, publishers, Indianapolis, Ind., xviii +374 pages.

The Childhood and Youth Series, edited by M. V. O'Shea of the University of Wisconsin, is a series rather more of educational than of sociological or medical interest. The present work is very wrell done and ought to form an excellent hand book for teachers, social workers, probation officers and other persons on the firing line of practical sociology.

There is a well chosen, brief bibliography and a convenient glossary of biological terms. Both Galtonian and Mendelian aspects of the problem are thoroughly presented.

Chapter 5 deals with the important question of hereditary modifications acquired directly by the body. The conclusion is that acquired modifications are not inherited. Special paragraphs deal with tuberculosis, immunity, nervous and mental disease. It is regarded as scientifically established that two individuals of tuberculous stock should not marry. A decision of the Supreme Court of New York is quoted to the effect that the fraudulent concealment of tuberculosis by a person entering into a marriage relation is ground for the annulment of the marriage. The matter of mental and nervous defects is treated in a separate chapter, Chapter 8.

Crime and delinquency are treated in Chapter 9. The importance of rigidly segregating the feeble-minded and of the early diagnosis of insanity, and the necessity that the insane should all be handled by psychiatrists are insisted upon. Feeble-mindedness when hereditary is regarded as possibly recessive (Goddard, Weeks)

The chapter on crime and delinquency deals especially with the morons, calls attention to the intensification of defects by inbreeding and holds the conception that vicious surroundings are not a sufficient explanation for degenerate stocks. Healy's work on The Individual Delinquent is approvingly quoted. That there are no special heritable crime factors is asserted and that there is 
no such thing as a born criminal. The book can be commended as dealing briefly with virtually all the best modern work on the topic.

Some insistence is made upon the importance of syphilis in the chapter (6) on prenatal influences.

\section{E. E. Southard.}

EUGENICS, Edgar Schuster, Warwick \& York, publishers, Baltimore, 264 pages, (Volume in "The Nation's Library Series).

The majority of the books in The Nation's Library Series so far published deal with sociological or economic considerations, and Schuster's Eugenics is far more a sociological work than a medical one. The outstanding feature of the book, which was first published in England in 1912, is the exceeding fairness with which the opposing views of Galton and Mendel are considered. The bibiliography includes chiefly works by Galton, Pearson and the Whethams. Favorable notice is given of the arguments of our American worker, Dr. Frederick Adams Woodș, with relation to the strong contrasts presented by royalty (contrasts supposed to be due to inborn determiners) and concerning the high percentage of distinguished relationship possessed by the Americans who have been put in the Hall of Fame.

The statement concerning the Solvay Institute, founded in 1902, and "established in a large and handsome building in the Parc Léopold at Brussels," "equipped with a scientific and administrative staff, a magnificent library, and a bibliography of every thing that appears on the subject of sociology" sounds a little pathetic in the midst of the German occupation. Its resources, according to Schuster, are at the disposal of persons making sociological researches, and possibly the German occupation may be regarded as an equivalent.

The practical measures by which eugenic principles may be applied are divided into positive and negative.

Schuster looks rather favorably upon certain marriage regulations and thinks that, besides protecting women from marrying men with venereal disease, the Norwegian proposals of Dr. Mjöen might also affect other eugenic objects such as the disclosure of epilepsy or of a tendency to insanity.

Schuster believes that there is ample knowledge to justify measures for the care and control of the feeble-minded and moral imbeciles to preclude the possibility of propagation. Taxation, he believes, should be adjusted so as not to penalize parenthood among the self-supporting classes. (Compare a certain rebate of income tax allowed to English fathers of families under the Finance Act of 1909 .)

The idea that a medical certificate of fitness for marriage should be obtained before permission to marry is accorded, is re- 